\title{
Low-level windshear associated with atmospheric boundary layer jets - Case studies
}

\author{
P.W. CHAN ${ }^{1 *}$, K.K. HON ${ }^{1}$ and Q.S. LI $^{2}$ \\ ${ }^{1}$ Hong Kong Observatory, 134 A Nathan Road, Kowloon, Hong Kong, China. \\ ${ }^{2}$ Department of Architecture and Civil Engineering, City University of Hong Kong, Tat Chee Avenue, Kowloon, Hong \\ Kong, China. \\ *Corresponding author; email: pwchan@hko.gov.hk
}

Received: April 3, 2020; accepted: September 4, 2020

\begin{abstract}
RESUMEN
Las corrientes en chorro en la capa límite atmosférica pueden provocar riesgos meteorológicos en el sur de China. En este estudio se documenta un cillazamiento del viento de bajo nivel vinculado con una corriente en chorro que puede impactar a una aeronave. Se analizan dos casos típicos del régimen del monzón del noreste: un chorro del este alterado por las montañas ubicadas al sur del Aeropuerto Internacional de Hong Kong, y el surgimiento repentino del monzón que provoca una corriente en chorro de bajo nivel del noreste. Los sistemas Doppler de detección por luz y distancia (LIDAR, por sus siglas en inglés) pueden captar las características de los cillazamientos de manera consistente con los informes de los pilotos y la información de vuelo. Son útiles para proporcionar avisos oportunos a las aeronaves. En este estudio en particular, el LIDAR capta una estructura de doble corriente en chorro en la capa límite atmosférica para un caso de viento del este, el cual no se había reportado antes en la literatura. El mecanismo físico que explica la presencia de una doble corriente en chorro aún es desconocido. También se estudia el desempeño de un modelo de predicción numérica del tiempo con alta resolución espacial $(200 \mathrm{~m})$ para pronosticar tanto la corriente en chorro como el cizallamiento de bajo nivel asociado. Se encontró que el modelo predice razonablemente bien las características del cizallamiento con algunas horas de anticipación y, en los casos estudiados, tiene capacidad para proporcionar alertas oportunas a las aeronaves.
\end{abstract}

\begin{abstract}
Jet streams in the atmospheric boundary layer may lead to hazardous weather over southern China. In this paper, the jet-related low-level windshear to be encountered by an aircraft is documented. Two typical cases under the northeast monsoon regime are considered, namely, easterly jet disrupted by the mountains to the south of Hong Kong International Airport, and outbreak of monsoon surge that produces a low-level northeasterly jet. The Doppler Light Detection and Ranging (LIDAR) systems are found to capture the corresponding windshear features very well, e.g., consistent with pilot reports and flight data. They are useful in providing timely alert to the aircraft. In particular, the LIDAR captures a double jet structure in the atmospheric boundary layer for the easterly wind case, which has not been reported in the literature before. The physical mechanism for the occurrence of the double jet is yet to be revealed. Moreover, the performance of a high spatial resolution $(200 \mathrm{~m})$ numerical weather prediction (NWP) model in predicting the jet and the associated low-level windshear is studied. The model is found to provide reasonable prediction of the windshear features at a few hours ahead, and, for the cases studied, shows skills in providing timely alerts to the aircraft.
\end{abstract}

Keywords: windshear, low-level jet, LIDAR. 


\section{Introduction}

A low-level jet within the atmospheric boundary layer occurs over southern China. A climatological study of low-level jets in the region may be found in Shu et al. (2018). The jet can be associated with the occurrence of heavy rain (Du and Chen, 2019). It is also found to be one of the major weather systems producing low-level windshear that could be encountered by aircrafts at the Hong Kong International Airport (HKIA), as discussed in HKO (2013). Detailed case studies of low-level jets in southern China are useful references to weather forecasters, whether serving the public or specialized user communities such as the aviation industry, in the operational prediction of hazards brought about by this weather phenomenon.

This paper documents two cases of low-level windshear encountered by aircrafts at HKIA associated with low-level jets under the northeast monsoon, which typically occurs in Hong Kong during winter, lasting perhaps until early spring. The phenomenology and synoptic prediction techniques of the northeast monsoon affecting Hong Kong are relatively well-established (Leung et al., 2015). Conventionally, the northeast monsoon may be categorized as a "northerly surge" (Lai, 1989) or an "easterly surge" (Chang, 1989), depending on the surface isobaric pattern and, consequently, the prevailing local wind direction. The first case, which will be described in detail in section 4 , is related to an "easterly surge": a strong easterly airstream associated with a ridge of high pressure lying along the southeastern coast of China. The second case, which will be covered in section 5 , occurs under a "northerly surge": an outbreak of intense north to northeasterly winds originated in mainland China. In both cases, windshear reports have been received for aircrafts arriving at and departing from HKIA. Such events have not been documented using measurements with a Doppler Light Detection and Ranging (LIDAR) system and with the prediction of a sub-kilometer resolution numerical weather prediction (NWP) model. This is the first time in the literature that the observational and forecast aspects of jet-related low-level windshear are described in detail. We hope that this document may serve as useful reference to aviation weather forecasters for providing windshear alerting at airports with similar climatological conditiond and terrain set-up. Hong Kong is located over southern China (Fig. 1a). HKIA is situated on a reclaimed island at the western part of the city and has two parallel runways, namely, the North Runway and the South Runway, with possible landing and take-off orientations of $70^{\circ}$ and $250^{\circ}$ from the north (Fig. 1b). Under the northeast monsoon, aircrafts mostly arrive using runway 07LA (i.e., at the North Runway from the west) and depart using runway 07RD (i.e., leaving from the South Runway towards the east). Pilots landing at or taking off from HKIA may provide windshear reports (also known as PIREP) to air traffic controllers whenever they encounter these phenomena, and the reports are forwarded to the Airport Meteorological Office.Two cases of low-level jets are described in this paper. The easterly jet is quite common in Hong Kong, occurring occasionally in the springtime. However, the double jet structure of the event described in this paper is rather rare and, to the knowledge of the authors, it is documented for the first in this paper. This phenomenon may occur during the northeast monsoon when there is an intense outbreak of the cold air in mainland China, which in turn may take place a few times during each winter. However, in some years, the intense outbreak of cold air is absent.The terrain map of Hong Kong, together with the location of the meteorological equipment, is shown in Figure 1d.

\section{Meteorological equipment}

A dense network of surface automatic weather stations is operated by the Hong Kong Observatory (HKO) inside and around HKIA. A distribution of the weather stations can be found in Figure 1b. Most of the stations measure surface wind using an anemometer with a height of around $10 \mathrm{~m}$ above ground level. There are also weather stations operated at the weather buoys, with a height of wind sensor of about 8 masl. At selected stations (e.g., the meteorological garden at the center of HKIA and the weather buoys), the other elements like temperature, dew point and pressure are also measured. The mountain top weather stations such as Nei Lak Shan and Yi Tung Shan (locations in Fig. 1b) are useful to capture the occurrence of low-level jets within the atmospheric boundary layer. They have a height of about 800-900 masl. Radiosondes are launched at the city center (at a place called King's Park about $20 \mathrm{~km}$ 

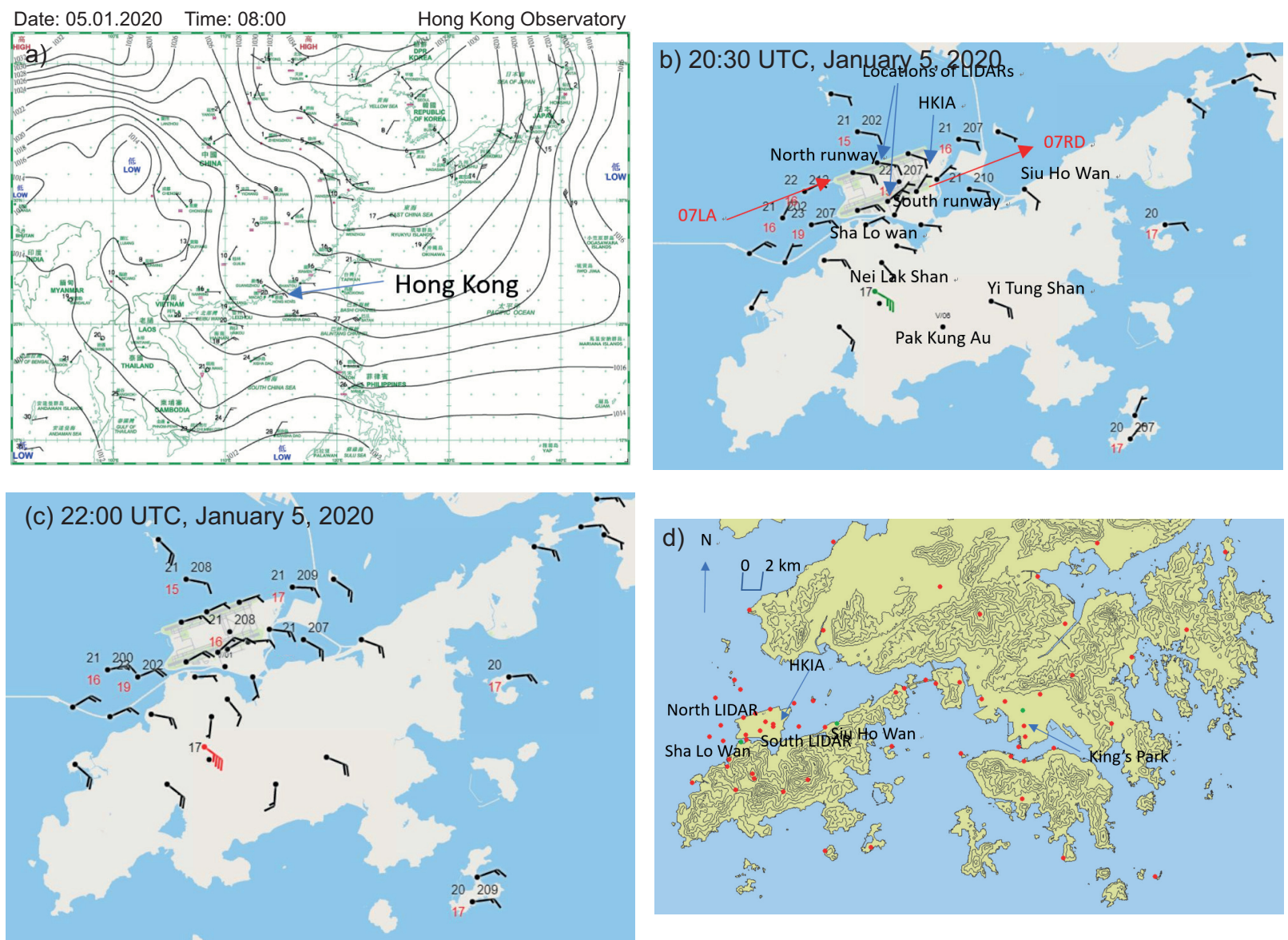

Fig. 1. (a) Surface isobaric chart in the morning of January 5, 2020. (b, c) Surface observations near the airport. Black numbers to the upper left and upper right of the stations show temperature and pressure, respectively. Wind barbs are in knots (full lines denote 10 knots and half lines 5 knots). The green wind barb represents a strong force and the red wind barb a gale force. (d) Terrain map of Hong Kong and equipment locations. Red dots signify surface anemometers and green dots wind profilers. Height contours are in $100 \mathrm{~m}$.

to the east of HKIA) twice a day for international exchange of upper-air wind, temperature, dew point, pressure, and horizontal wind. Raw data are available up to every $2 \mathrm{~s}$ (which converts to a height separation of about $10 \mathrm{~m}$ in the boundary layer) so that the low-level atmospheric structure can be observed clearly. However, data are available at limited times, normally 00:00 and 12:00 UTC (Hong Kong Time $[\mathrm{HKT}]=\mathrm{UTC}+8 \mathrm{~h}$ ) of the day only. To measure low-level winds more continuously, boundary layer type radar wind profilers are operated by HKO at a number of places in Hong Kong. Two are located near HKIA, namely, Siu Ho Wan and Sha Lo Wan (Fig. 1b) (Chan and Chan, 2004). Wind data are available in low mode starting from about 120 masl up to about 1500 masl, with a gate spacing of about $60 \mathrm{~m}$. Measurements are performed every $10 \mathrm{~min}$. The wind profilers use vertical and oblique beams (at $15^{\circ}$ from the vertical) with radio frequency of $1299 \mathrm{MHz}$ for measuring the three wind components with the Doppler beam swinging technique.The Sha Lo Wan wind profiler is also equipped with a radio acoustic sounding system (RASS), which emits audible sound in the atmospheric boundary layer whose waves are tracked by the radio beams from the vertically pointing radar. It gives the vertical virtual temperature profile up to about $2 \mathrm{~km}$ above the surface. The temperature profile is useful in depicting isothermal layer/temperature inversion as a result of, e.g., the Foehn effect.Though the atmospheric wind structure within the boundary 
layer could be provided by the radar wind profilers, the 10-min averaging required is not able to capture the rapidly changing winds as a result of mechanical turbulence generated by the mountains near HKIA, which was a lasting problem for capturing low-level windshear until the Doppler LIDAR was introduced at HKIA (Shun and Chan, 2008). LIDAR is a powerful tool for measuring the rapidly changing winds through the Doppler effect by tracking the movement of aerosols in the air, which are shifted by the wind. The LIDAR at HKIA uses laser beams with a wavelength of $1.5 \mu \mathrm{m}$, providing Doppler velocity output data up to a frequency of $10 \mathrm{~Hz}$. It is configured to scan in three modes: plan position indicator (PPI) of $3^{\circ}$ and $6^{\circ}$ from the horizon; range height indicator (RHI) at azimuth angles of $163^{\circ}$ (in the direction of Pak Kung $\mathrm{Au}$ [Fig. 1b]); and $258^{\circ}$ (along the runway direction). The two LIDARs at HKIA are shown in Figure 1b, each serving a runway of HKIA. LIDAR is a major tool for detecting and alerting low-level windshear at HKIA.The meteorological equipment serving the airport is calibrated every year in accordance with the requirements of a quality management system. Before its data were analyzed in this paper, it was manually checked to ensure quality.

\section{NWP model}

In terms of forecasting, the HKO operates the Aviation Model (AVM) (Chan and Hon, 2016), which is a sub-kilometer resolution implementation of the Weather Research and Forecast (WRF) (Skamarock and Klemp, 2007) model for fine-scale short-term weather prediction at the HKIA. The AVM comprises two single-nested domains at 600 and $200 \mathrm{~m}$ horizontal resolution and provides hourly-updated forecasts up to $\mathrm{T}+6$ to $\mathrm{T}+9 \mathrm{~h}$ ahead. In this paper, we deal with the 200-m resolution inner domain called AVM-HKA, which is centered around HKIA. Since the AVM is run operationally in real-time, the system has undergone some updates and enhancements in the time period between the cases described in sections 4 and 5. Most notably, the WRF model v. 3.4.1, which was in use during 2015, was updated to v. 3.9.1 in 2020. Some comparisons have been made for model runs between the two versions and no significant differences were found (not shown). The domain size of AVM-HKA was also enlarged from $253 \times 253$ horizontal grid points (covering only the immediate vicinity of HKIA) in 2014 to $581 \times 581$ grid points (covering the whole Hong Kong territory) since 2018. As a compromise between vertical resolution and constraints in computational resources, 42 eta levels (i.e., terrain following coordinates) were used, out of which at least 10 were below $1000 \mathrm{~m}$ at the time of model initialization. For data assimilation, the 3-D variational scheme based on WRFDA is used to ingest conventional surface and upper-air observations maintained by $\mathrm{HKO}$ at and around HKIA, as well as over various parts of Hong Kong. Model settings of AVM-HKA follow that of Hon (2018). Key configurations include the WRF double-moment six-class microphysics (WDM6) scheme (Lim and Hong, 2010), RRTMG schemes for short- and long-wave radiation (Iacono et al, 2008), and the Noah land surface model (Niu et al., 2011). Given the high horizontal resolution, cumulus parameterization and boundary layer schemes are not used (the latter being the so-called "large eddy simulation mode"). Local adaptations (based on high resolution terrain data $[100 \mathrm{~m}$ or less]) of local terrain data provided by the Lands Department of the Hong Kong SAR Government are applied to the USGS 3-second topography and MODIS land use data to cater for urbanization and changes in coastline. In addition to conventional forecast parameters such as surface and upper-air winds, temperature, and humidity, AVM-HKA also provides specialized products including simulated radar reflectivity (Hon et al., 2019) and low-level windshear potential forecast based on simulated LIDAR return. While the latter capability has been examined in detail both in the form of case studies (Chan et al., 2019) and year-long verification (Hon, 2019), this is the first time that windshear cases under the northeast monsoon regime in Hong Kong are specifically dealt with. The simulated winds are resolved along the directions of the laser beam of the LIDAR to obtain the radial component of wind velocity with respect to the LIDAR's location. Such radial velocities are color-coded in the same way as the LIDAR's measured radial velocities to obtain the simulated LIDAR pictures.

\section{Easterly wind case - January 5, 2020}

Synoptically on that day, a ridge of high pressure over the southeastern coast of China brought strong easterly winds to Hong Kong (Fig. 1a). Windshear reports 
were received from two aircrafts, one at 12:30 UTC arriving at HKIA on the 07L runway at a height of 500 feet with a headwind gain of 15 knots. Another was reported over runway $07 \mathrm{RD}$ at 14:00 UTC, 500 feet height and a 20 knots headwind gain. There was another turbulence report from a departing aircraft from 07RD at a height of 1000 feet (about 1 nautical mile from the runway threshold), which encountered moderate turbulence. We mainly focused on the two windshear reports, though turbulence also occurred because of the terrain-disrupted easterly airstream caused by the mountains south of HKIA. Figure 1 b, c shows the surface wind distributions near HKIA at the time of the two windshear reports. It can be seen that the winds were rather smooth over the runways and the surrounding sea. Based only on ground-based wind data, the occurrence of a low-level windshear could not be suspected. The only hint was a strong to gale force wind over the mountain top, which indicates there was a low-level jet within the atmospheric boundary layer and the wind could be disrupted over the HKIA region due to mechanical turbulence from the mountains at the south of the airport.The low-level atmospheric structure is also revealed in the radiosonde measurement at King's Park at 12:00 UTC, January 5, 2020 and at 00:00 UTC on the next day (Fig. 2a, b, respectively). A jet of about $13-15 \mathrm{~ms}^{-1}$ at a height of about $1000 \mathrm{~m}$ can be seen in both measurements. At roughly the same height, temperature inversions of $3^{\circ}$ to $5^{\circ}$ can be analyzed in the thermodynamic diagrams. The jet and the temperature inversion appear around the height of the mountains to the south of HKIA. As a result, terrain disruption of the airflow is expected and there is a high chance that a low-level windshear is encountered by the aircraft. The low-level jet also shows up nicely in the wind profiler measurement. For Sha Lo Wan, there was a jet with strong winds (colored in blue) around 500 to 1000 masl in the evening of January 5, 2020 (Fig. 3a). It remained there for several hours and appeared to descend to the ground around midnight. A similar observation of the low-level jet was depicted by the Siu Ho Wan wind profiler, with the jet occurring between 400 and 1200 masl (Fig. 3c).The RASS at Sha Lo Wan shows that the virtual temperature profile follows a dry adiabatic lapse rate at and below $500 \mathrm{~m}$, and a roughly isothermal for heights above (Fig. 3b). The isothermal may be consistent with the occurrence of temperature inversion above $500 \mathrm{~m}$ as shown in the upstream, undisturbed airflow at King's Park, but may also be related to the Foehn effect because of a descending low-level jet across the mountains to the south of HKIA. More information is required to establish this Foehn wind conjecture.The LIDARs show up nicely the wind distribution around HKIA and the headwind changes along the flight paths. In this case, they successfully provide early alerts to aircrafts encountering low-level windshear. LIDAR velocity imagery is shown in Figure $4 \mathrm{a}, \mathrm{b}$ for 12:30 and 14:00 UTC, January 5, 2020. The middle panels are the $3^{\circ}$ and $6^{\circ}$ PPIs. In general, they show the strong easterly airstream over the airport area. It is interesting to note that, for the 07RWY left panel at 12:30 UTC (Fig. 4a), there are two orange blobs on the western part of the airport, instead of the one that is expected from the prevalence of a single easterly jet. It is suspected that there may be another elevated easterly jet at high altitude, which could be examined later from the RHI scans. In any case, because of this double jet structure, the headwind profile shows a rather rare feature, namely, two peaks and one trough in the middle, as shown in the 07LA headwind profile at 12:30 UTC. A headwind gain of 20 knots is automatically detected by the windshear algorithm and the windshear alert was generated timely for alerting aircrafts in flight. In general, the LIDAR-based windshear alert and the pilot report are consistent with each other.The 07RD windshear report is more straightforward in terms of the atmospheric boundary layer wind structure. The LIDAR headwind profile is given in Figure $4 \mathrm{~b}$ for runway $07 \mathrm{RD}$. There is a single peak in the profile, which is associated with the low-level jet, a single jet structure. When the aircraft departs, it encounters the jet and headwind gain could be expected. The LIDAR-based windshear alert reports a headwind gain of 16 knots, which is generally consistent with the pilot report. It is also noted that the headwind profile at 07LA is a single peak structure, and the $3^{\circ} \mathrm{PPI}$ scans show only a single blob (orange red for RWY07 and blue for RWY25). As revealed by the LIDAR PPIs at other times (not shown), the double jet structure only occurred for less than $30 \mathrm{~min}$. It is a rather transient structure and had not been observed before at HKIA, according to the experience of the authors. To study the double jet structure further, RHI plots from the south runway LIDAR are also examined. From the 

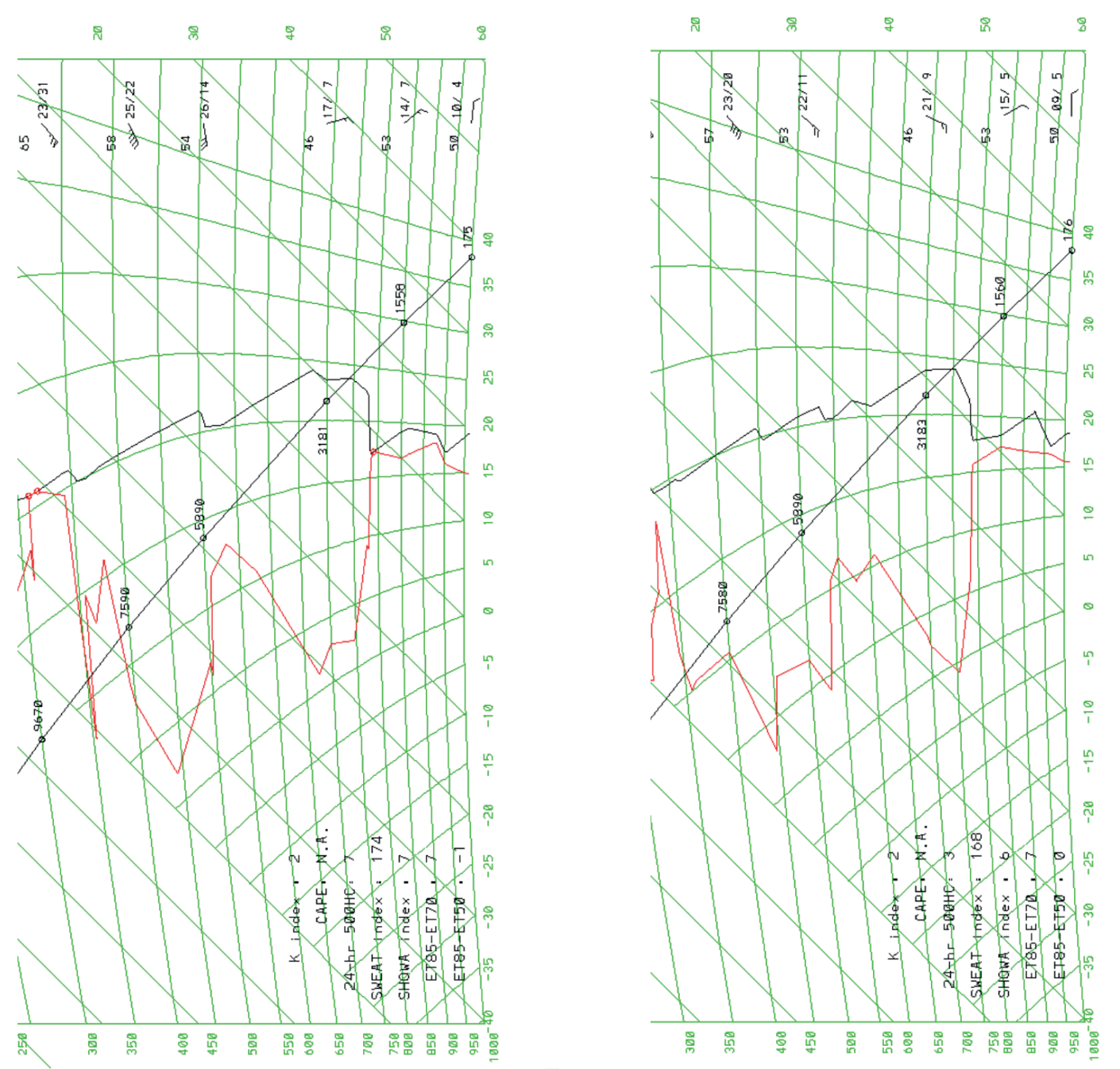


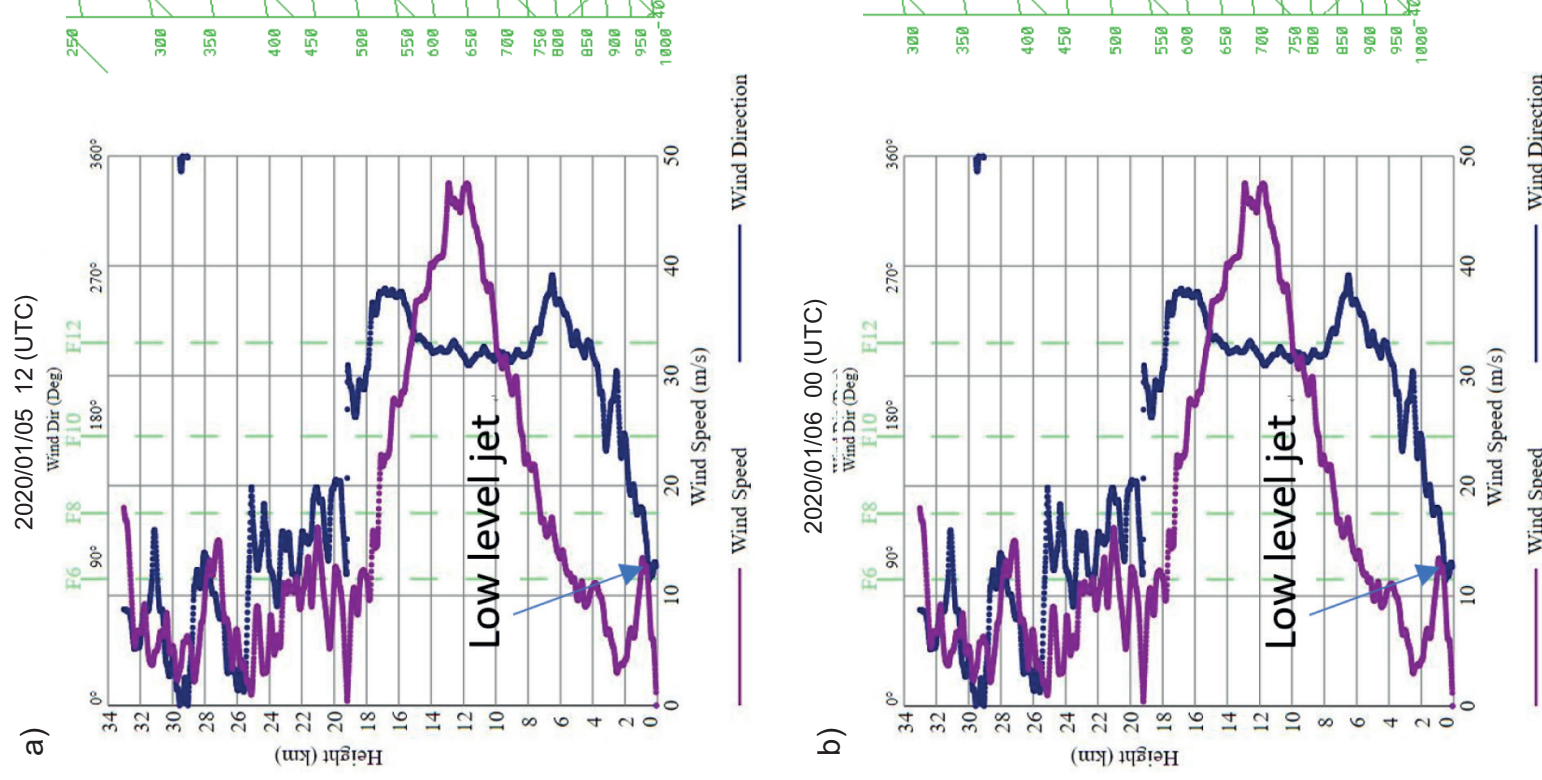

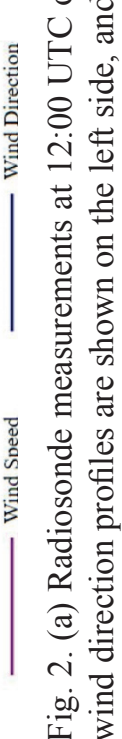



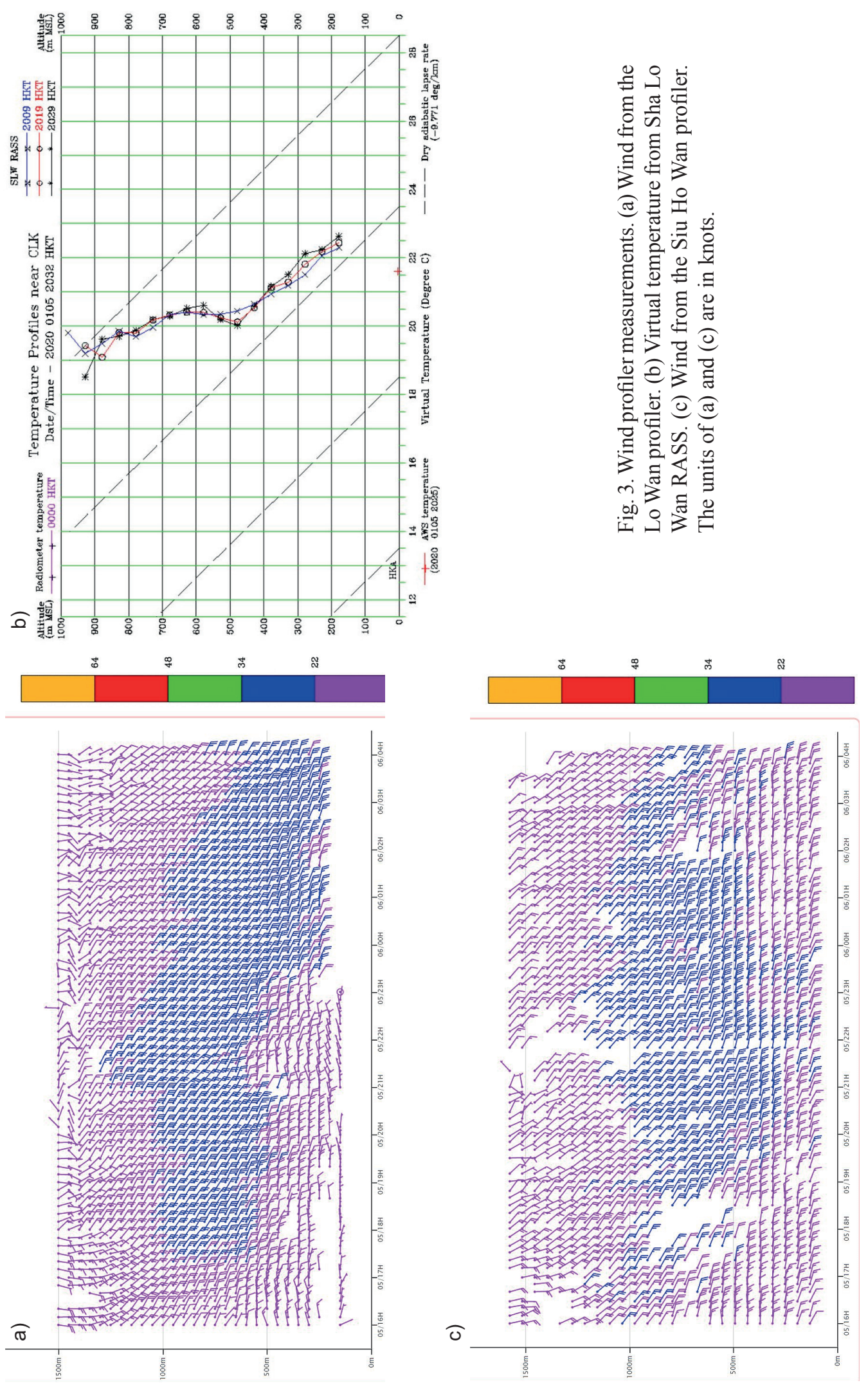
(a) 12:30 UTC, January 5,2020
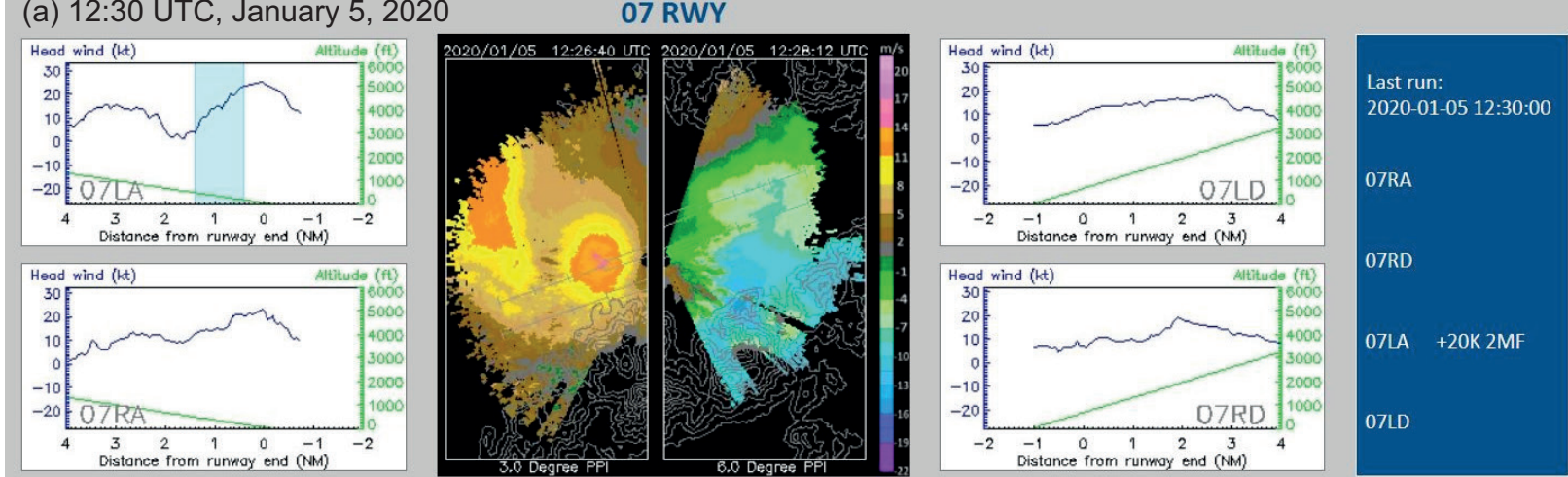

25 RWY
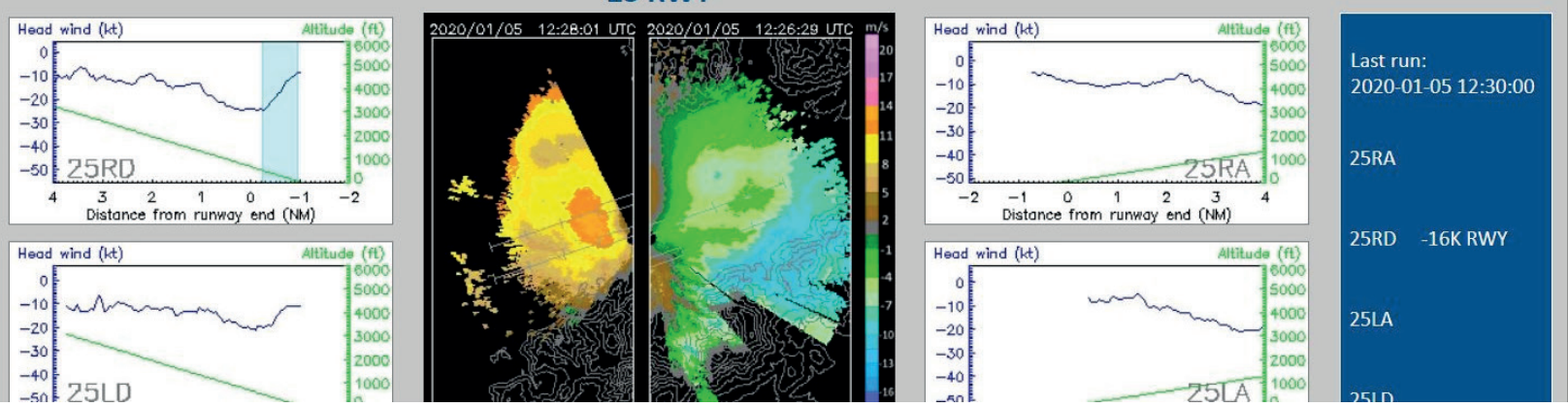

(b) 14:00 UTC, January 5, 2020
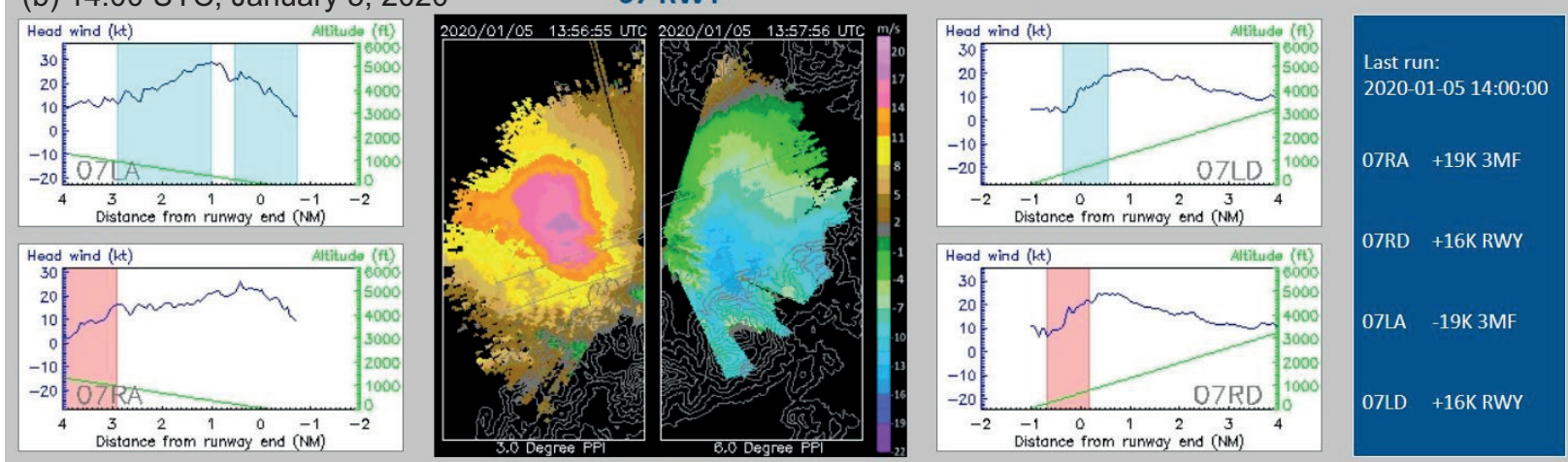

25 RWY
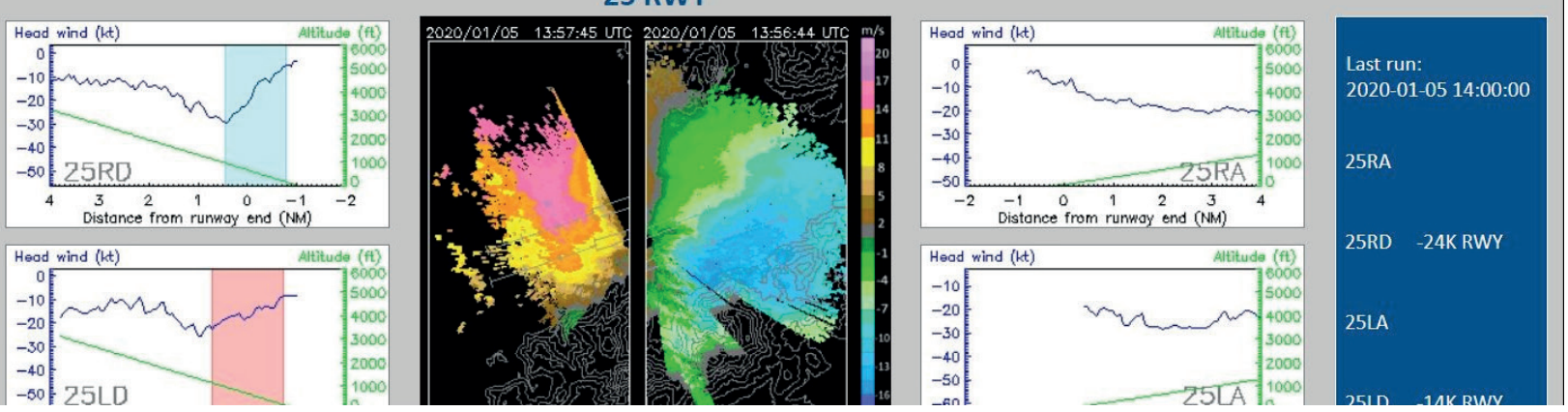

Fig. 4. Wind shear alerting panels from LIDAR. In each panel, the center figures show PPI velocity imageries from the LIDAR at $3^{\circ}$ and $6^{\circ}$ elevation. Figures on both sides are the headwind profiles of the various runway corridors. Windshear ramps are highlighted in the headwind profiles. Numbers on the right side depict the corresponding windshear alerts. 
$163^{\circ} \mathrm{RHI}$ plot (Fig. 5a), there appears to be a rising and then descending jet for the easterly wind. This descending jet may be supportive of the occurrence of
Foehn wind at the Sha Lo Wan RASS, as discussed above. For the $258^{\circ}$ RHI plot (Fig. 5b), the easterly jet appears to have split into two parts at one end, one

(a) $\mathrm{RHI}$ at an azimuth angle of $163^{\circ}$ Doppler Velocity RHI/ HKO LIDAR HKG2

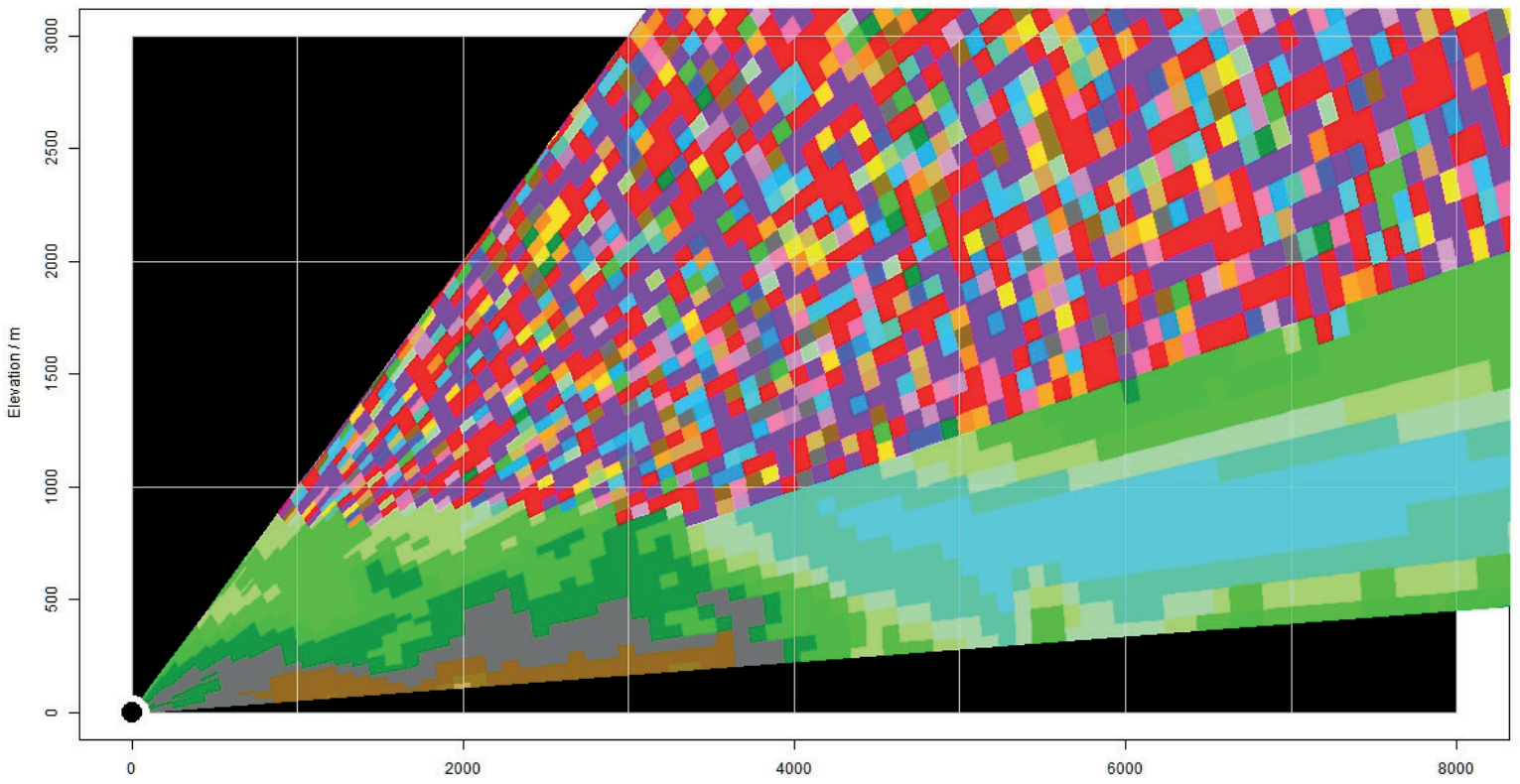

(b) $\mathrm{RHI}$ at an azimuth angle of $258^{\circ}$

Horizontal Distance / $\mathrm{m}$ Doppler Velocity RHI/HKO LIDAR HKG2

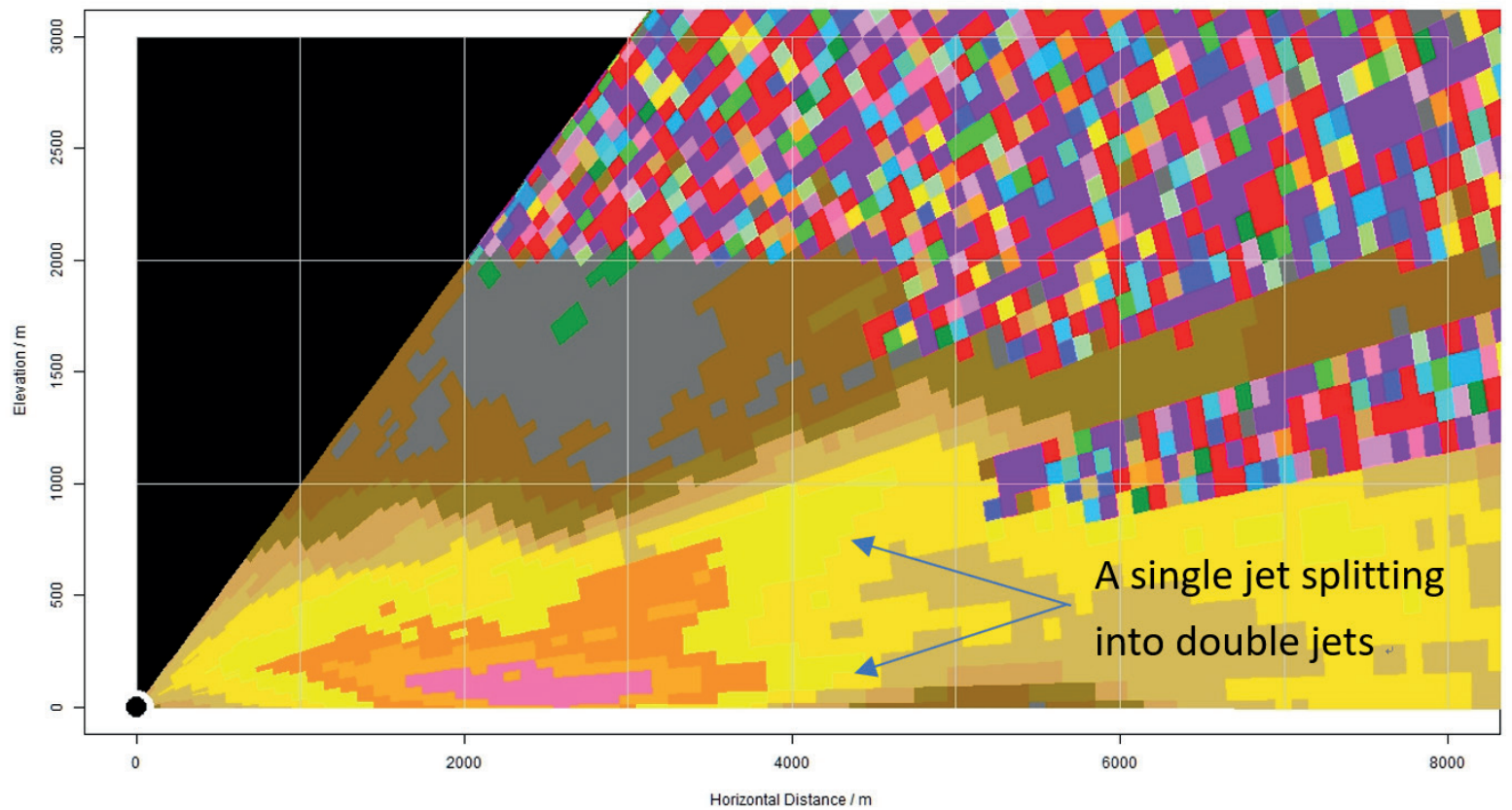

Fig. 5. RHI velocity imageries of the south runway LIDAR at the respective azimuth angles from the north. (a) Vertical cross section across the Pak Kung Au valley. (b) Vertical cross section over the runway corridor to the west of the south runway (07RA). The velocity scale is the same as in Figure 4. 
above and the other below 500 masl. This is consistent with the double jet structure as shown in the PPI scan. This kind of splitting had not been observed before at HKIA and the reasons for its occurrence need to be examined further. It would be interesting to see if such a windshear could be predicted by the high-resolution NWP model. The simulated LIDAR panels are shown in Figure 6. Figure 6a shows the simulation result after $2 \mathrm{~h}$ based on the initial time at 11:00 UTC on January 5, 2020. The two-peak structure is observed

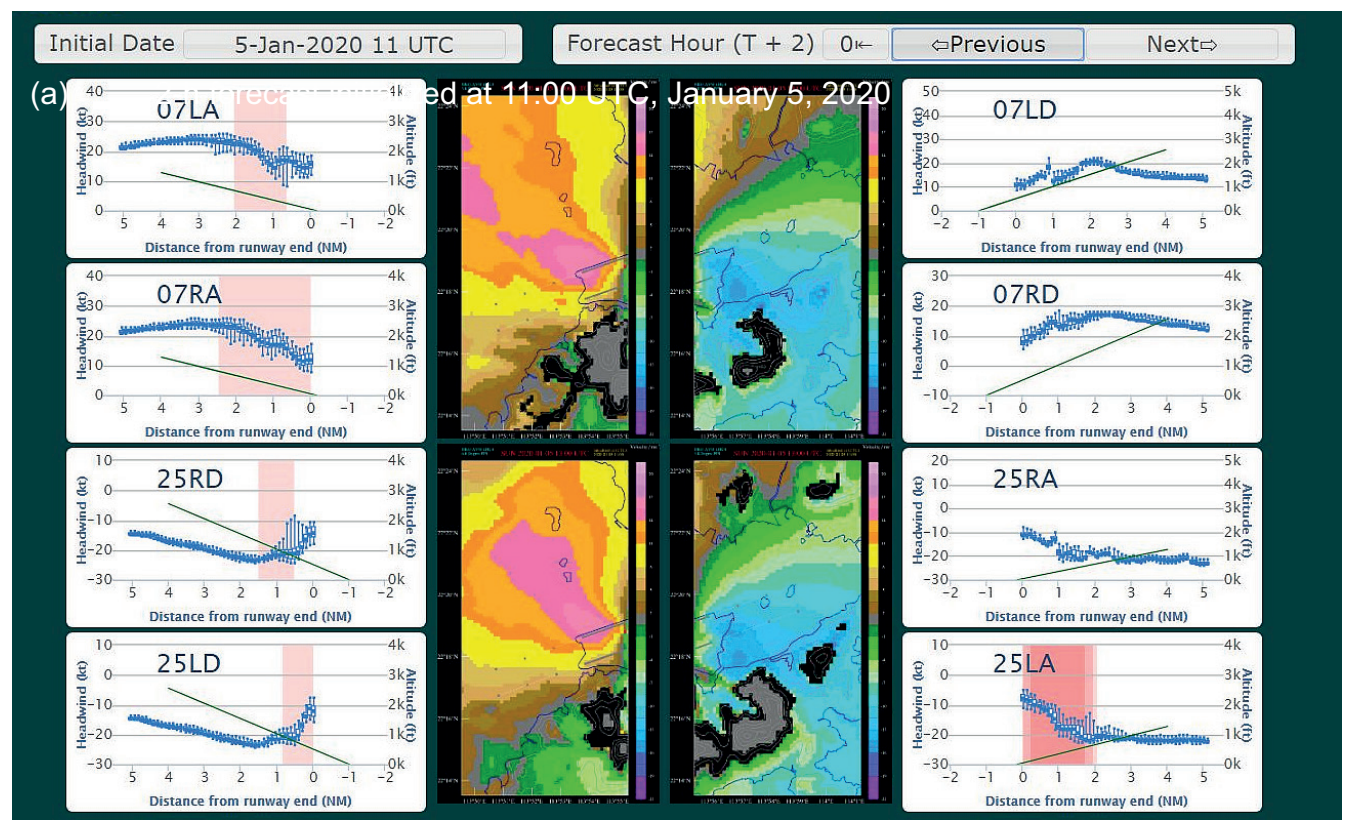

(a) 2-h forecast initialized at 11:00 UTC, January 5, 2020

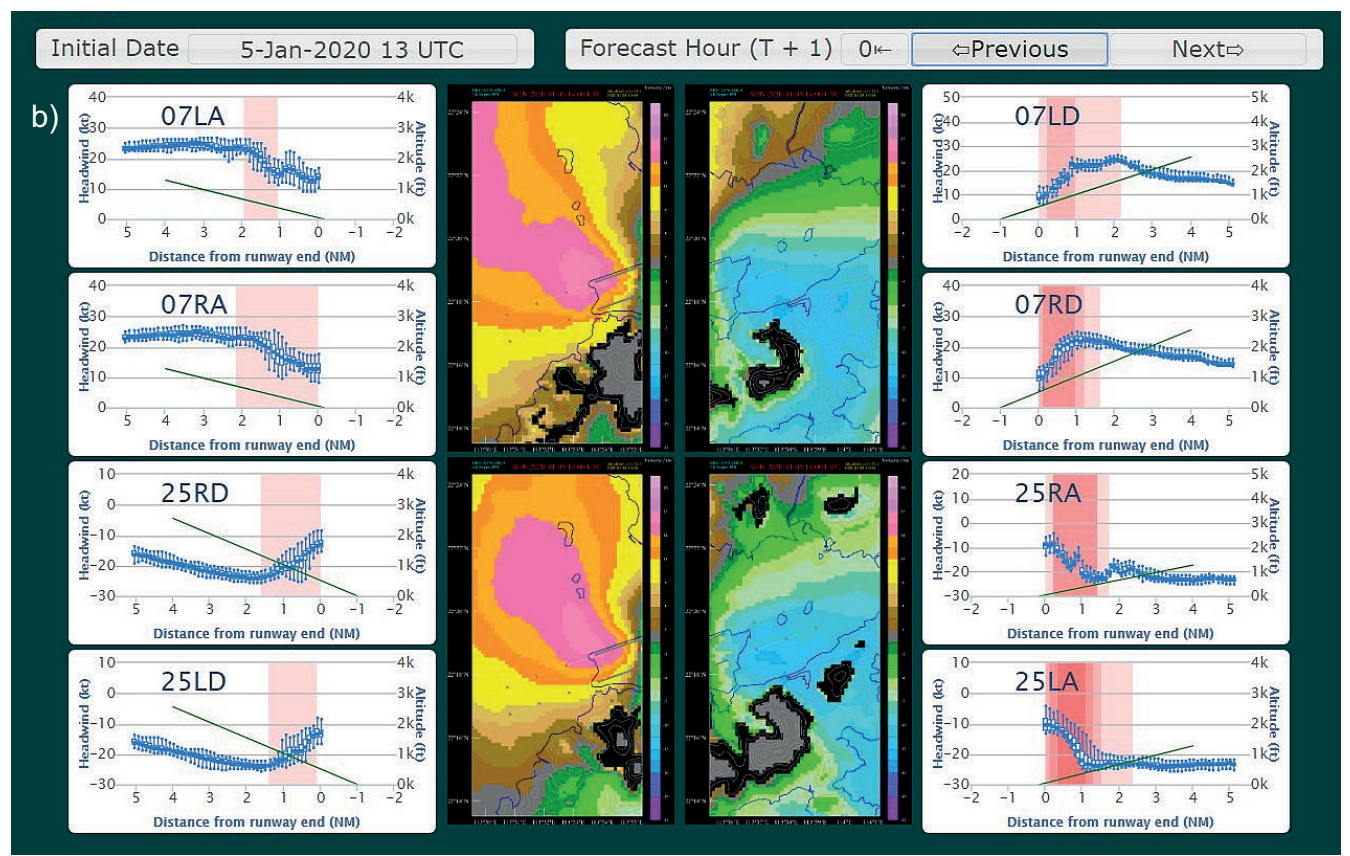

(b) 1-h forecast initialized at 13:00 UTC, January 5, 2020

Fig. 6. Simulated LIDAR and headwind velocity panels using the high resolution NWP model. The structure of the panel is the same as that in the actual LIDAR observations shown in Figure 4. 
in the $3^{\circ}$ PPI scan at RWY07. For the headwind profile at $07 \mathrm{LA}$, there is tiny double peak structure, though the headwind change from the peak to the trough is not as high as the actual LIDAR observations. Figure $6 \mathrm{~b}$ shows the $1-\mathrm{h}$ simulation result as initialized at 13:00 UTC on January 5, 2020. The single headwind peak associated with the jet shows up nicely over runway 07RD. In general, the high-resolution NWP model appears to have skills in predicting the occurrence of a low-level windshear at HKIA.To study the double jet structure in more detail, two vertical cross sections are made in the simulated wind field at HKIA. The 2-h forecast initialized at 11:00 UTC on January 5, 2020 is considered. The simulated LIDAR PPI scans and the locations of the vertical cross sections are shown in Figure 7a while Figure $7 \mathrm{~b}$ shows the vertical cross section along the easterly flow. There are two pink blobs in Figure 7a over the panel of RWY07, which are associated with two areas of higher wind speeds in Figure 7b. In Figure 7c two jets can be observed on the vertical cross section along the runway direction, but they are closer to the LIDAR location as compared to the actual LIDAR observations. The transient double jet structure shows up in the NWP model, but the location is not quite the same as in reality. More numerical simulation experiments are being conducted to further understand the double jet structure. The occurrence of a double jet has been previously reported in the summer monsoon regime associated with heavy rainfall over Southern China (Du and Chen, 2018), but the authors are not aware of similar occurrences reported during the winter monsoon. Moreover, in the above-mentioned summer monsoon study, the double-jet structure is delineated to occur at two distinct isobar levels, comprising a synoptic jet at $850-700 \mathrm{hPa}$ (roughly between 1500 to $3000 \mathrm{~m}$ ) and a boundary layer jet around $925 \mathrm{hPa}$ (about $1000 \mathrm{~m}$ ). The boundary layer wind structure observed and simulated in this case would be much smaller in spatial scale (occurring wholly below $1000 \mathrm{~m}$ ) and hence posing considerably greater challenges to its observation and modeling.

\section{Northerly surge case - 16 December 2014} An outbreak of intense northeast monsoon occurred on December 16, 2014. From the surface synoptic charts (Fig. 8, b), densely packed surface isobars appear over southern China. The northerly winds remain strong in the next morning. This is a typical situation for the occurrence of cold weather in Hong Kong during winter. From the radiosonde ascent measurements at 12:00 UTC on December 16, 2014 (Fig. 9a) and the next morning (00:00 UTC on December 17, Fig. 9b), a low-level jet occured at about 1000 masl with a magnitude of 13 to $18 \mathrm{~ms}^{-1}$. Several weak temperature inversions (around $2^{\circ}$ ) appear at about 500 and 1000 masl at 12:00 UTC on December 16, 2014, which were ground-based on the next morning. There are several mountains upstream HKIA in the northeast to north direction, though much lower in height (about $300 \mathrm{~m}$ ). Terrain disruption may play a role in the occurrence of turbulent airflow over HKIA, but the low-level jet could cause itself significant headwind changes to aircrafts.A typical headwind profile over that night is given in Figure 10. For 07RD, there is a single peak structure associated with the jet and significant windshear is expected as the aircraft departs from the airport. In fact, between 17:00 and 22:00 UTC on December 16, 2014, a total of six aircrafts reported encountering a windshear over $07 \mathrm{RD}$, at a height between 1000 and 2000 feet and wind changes of +20 (gain) to -15 (loss) knots. Flight data are obtained from aircrafts as shown in Figure 11, where it can be seen that the headwind profile between LIDAR and the aircrafts is very consistent. On the other hand, while displaced from the runway direction a bit for the wind profiler at Siu Ho Wan, the headwind profile is not consistent with observations. As a result, windshear alerting requires headwind measurements right at the location of the flight path. A distance away from the flight path may not be sufficient to capture the headwind changes encountered by the aircraft. The high-resolution NWP model again does a good job in capturing the windshear associated with the low-level jet. Some typical forecasts of the model are given in Figure 12. It can be seen that simulated and actual LIDAR PPI images are very similar. Moreover, over 07RD, the simulated headwind profile captures the single peak structure, and the model is sufficient to produce realistic windshear alerts from the aircraft 4 to $6 \mathrm{~h}$ ahead. 

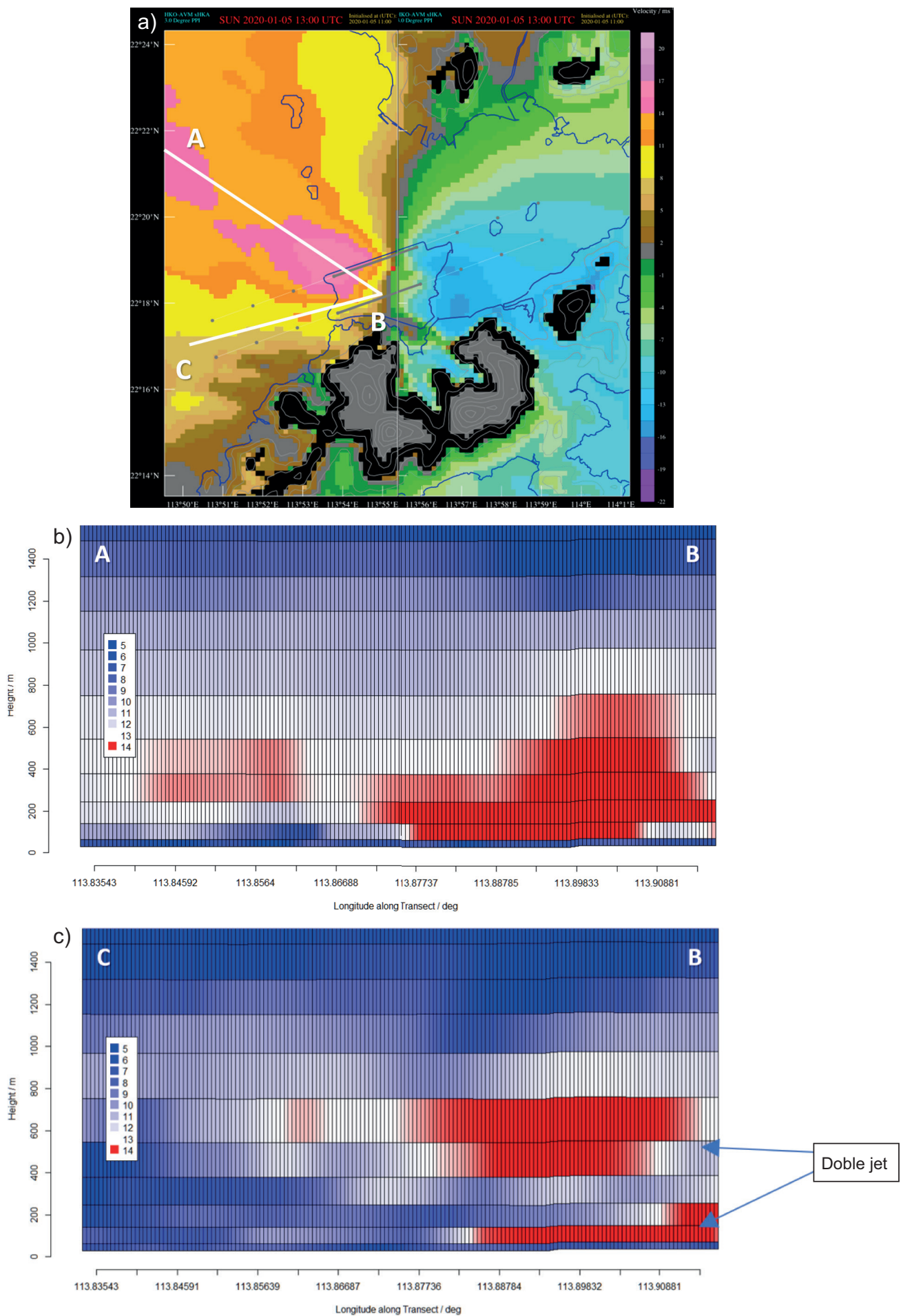

Fig. 7. Simulated $3^{\circ}$ elevation PPI velocity imagery for a model run initialized at 11:00 UTC on January 5, 2020. Forecast is for $2 \mathrm{~h}$. (a) Locations of the vertical cross sections. (b, c) Cross sections of wind speed. 


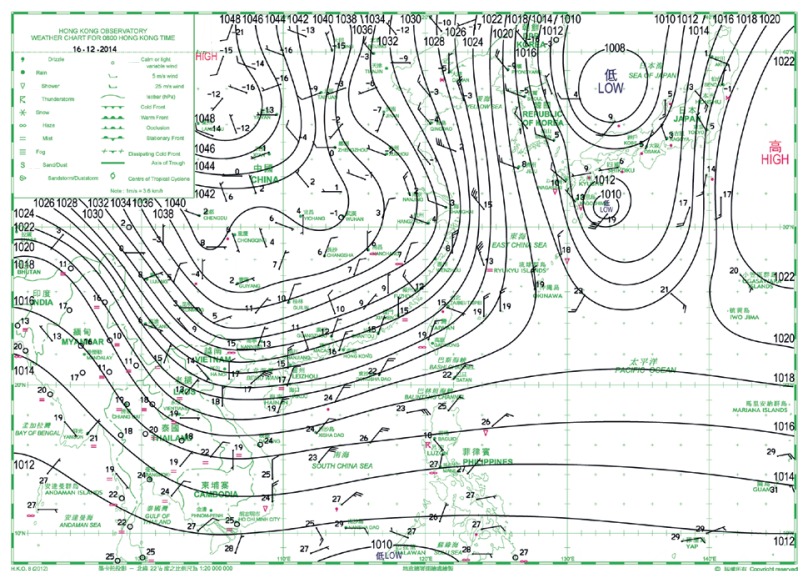

a) 00:00 UTC, December 16, 2014

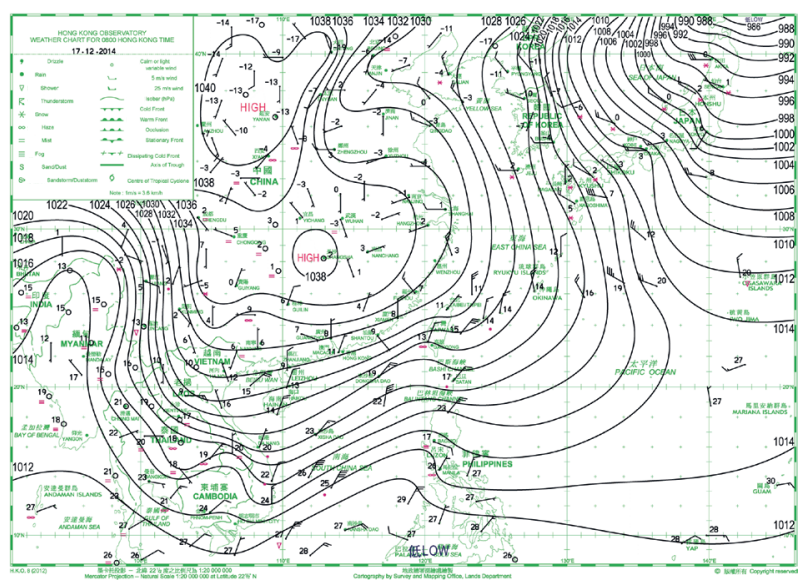

(b) 00:00 UTC, December 17, 2014

Fig. 8. Surface isobaric charts for the case of intense northeast monsoon.
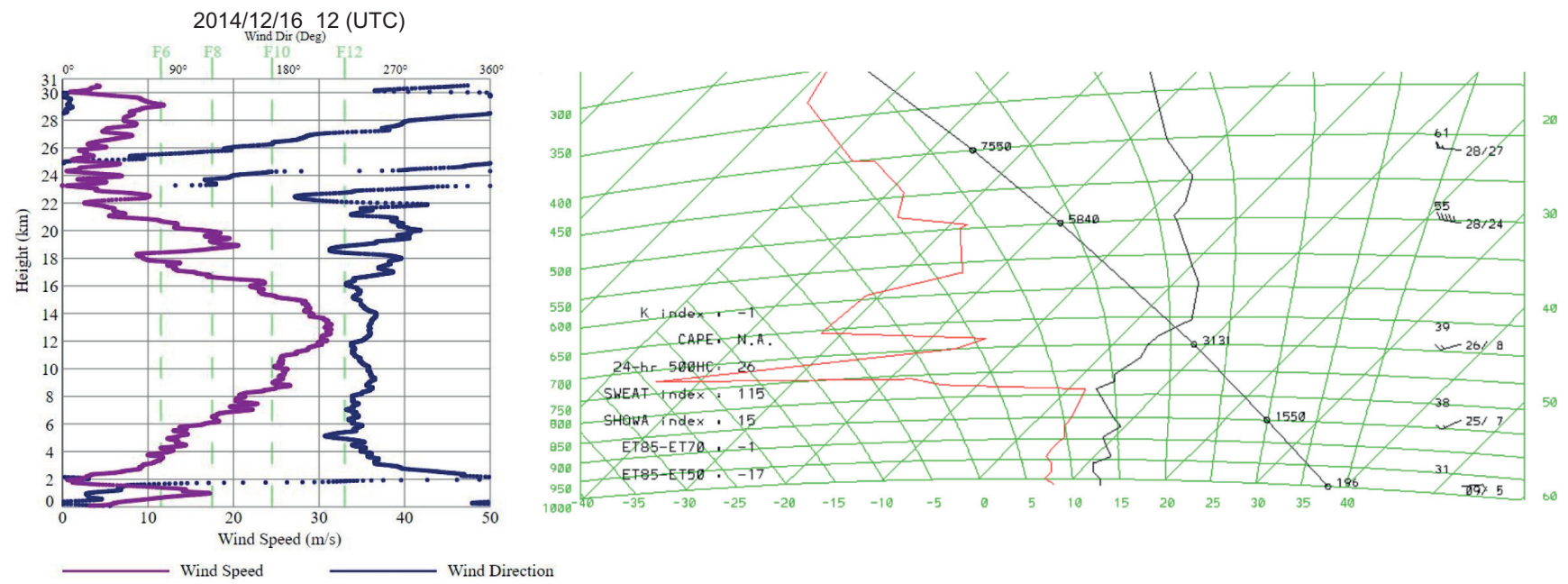

(a) 12:00 UTC, December 16, 2014

2014/12/17 00 (UTC)
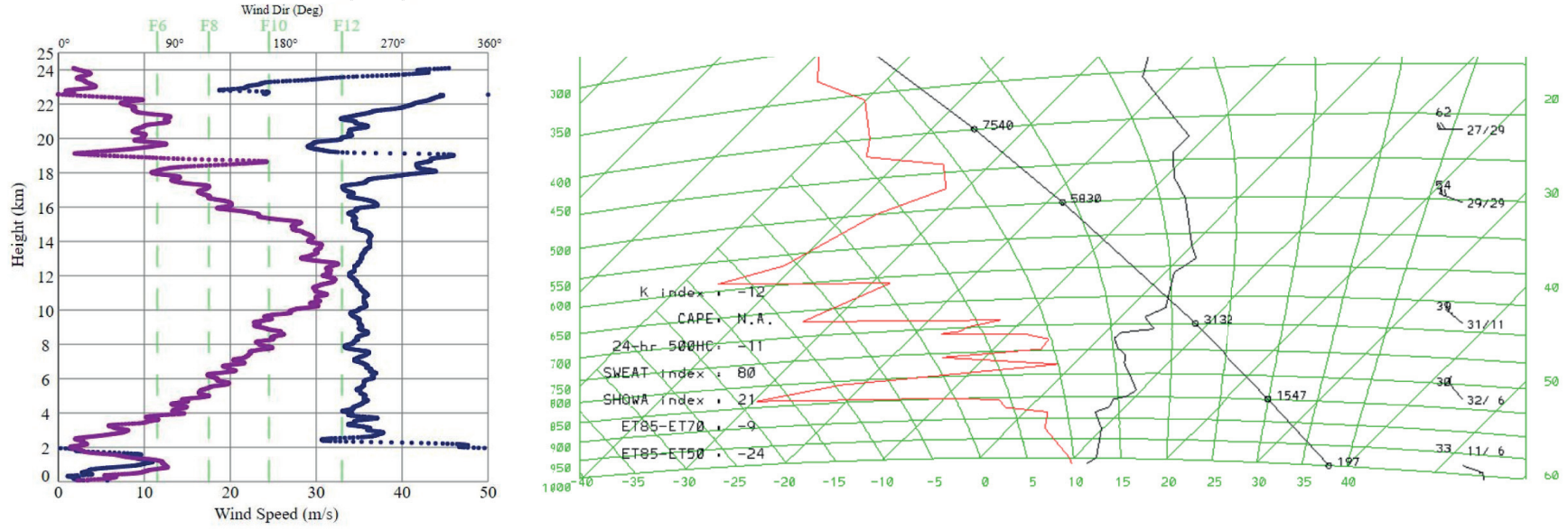

(b) 00:00 UTC, December 17, 2014

Fig. 9. Radiosonde measurements for the 2014 case (similar to Fig. 2). 


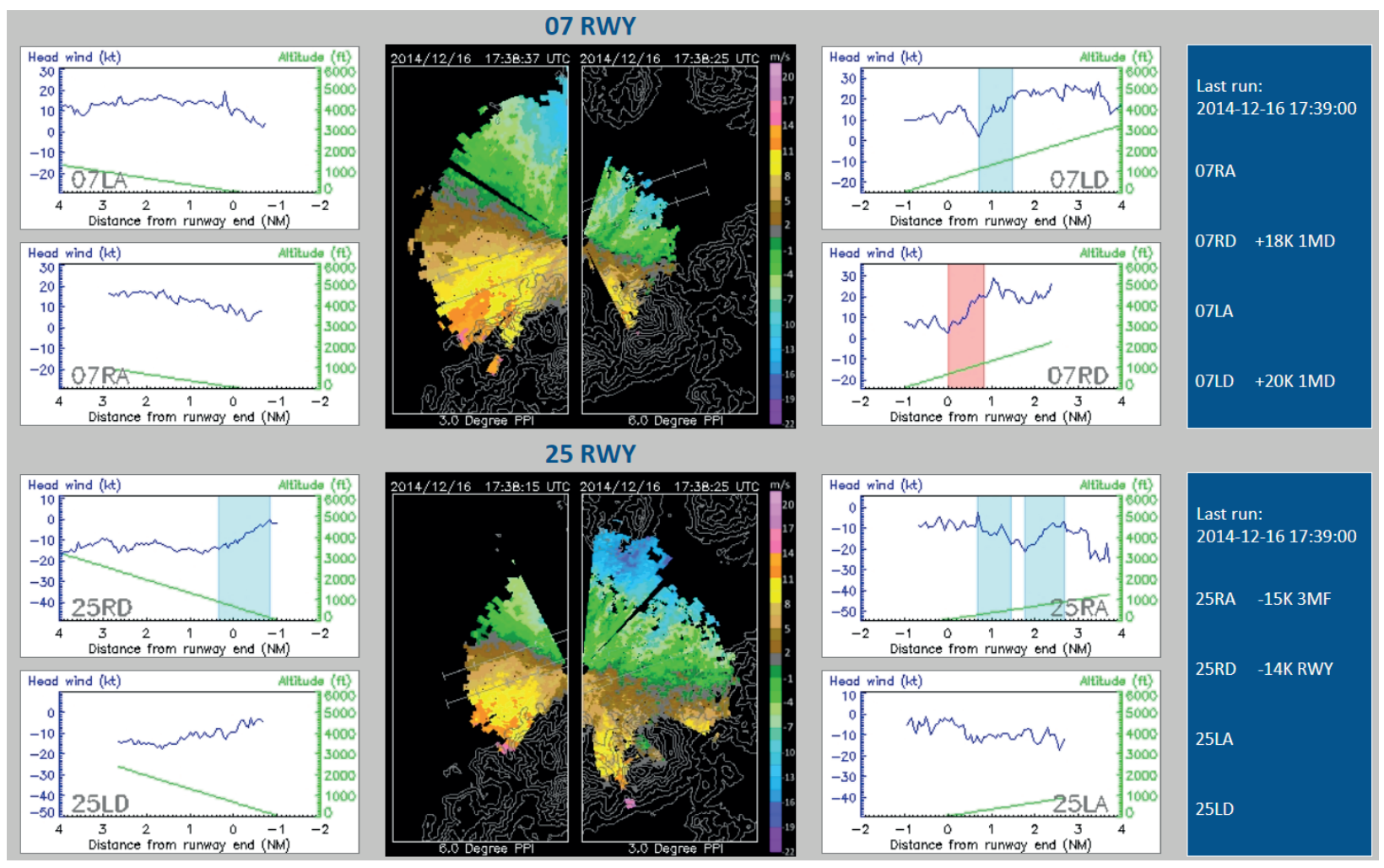

Fig. 10. LIDAR windshear alerting panel at 17:39 UTC, December 16, 2014 (similar to Fig. 4).

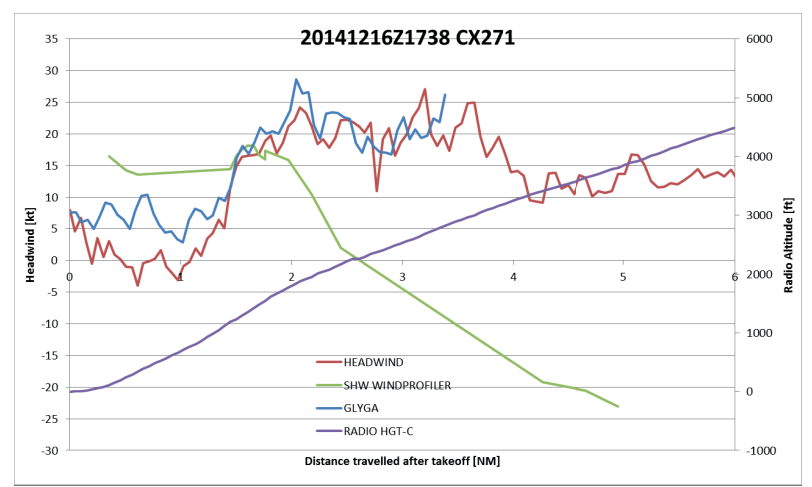

Fig. 11. Height/headwind profile as a function of distance from the takeoff location for a flight encountering low-level windshear (17:38 UTC, December 16, 2014). The headwind profiles include those from the aircraft (brown), LIDAR (blue) and the Siu Ho Wan wind profiler (green). The height profile is in purple. 

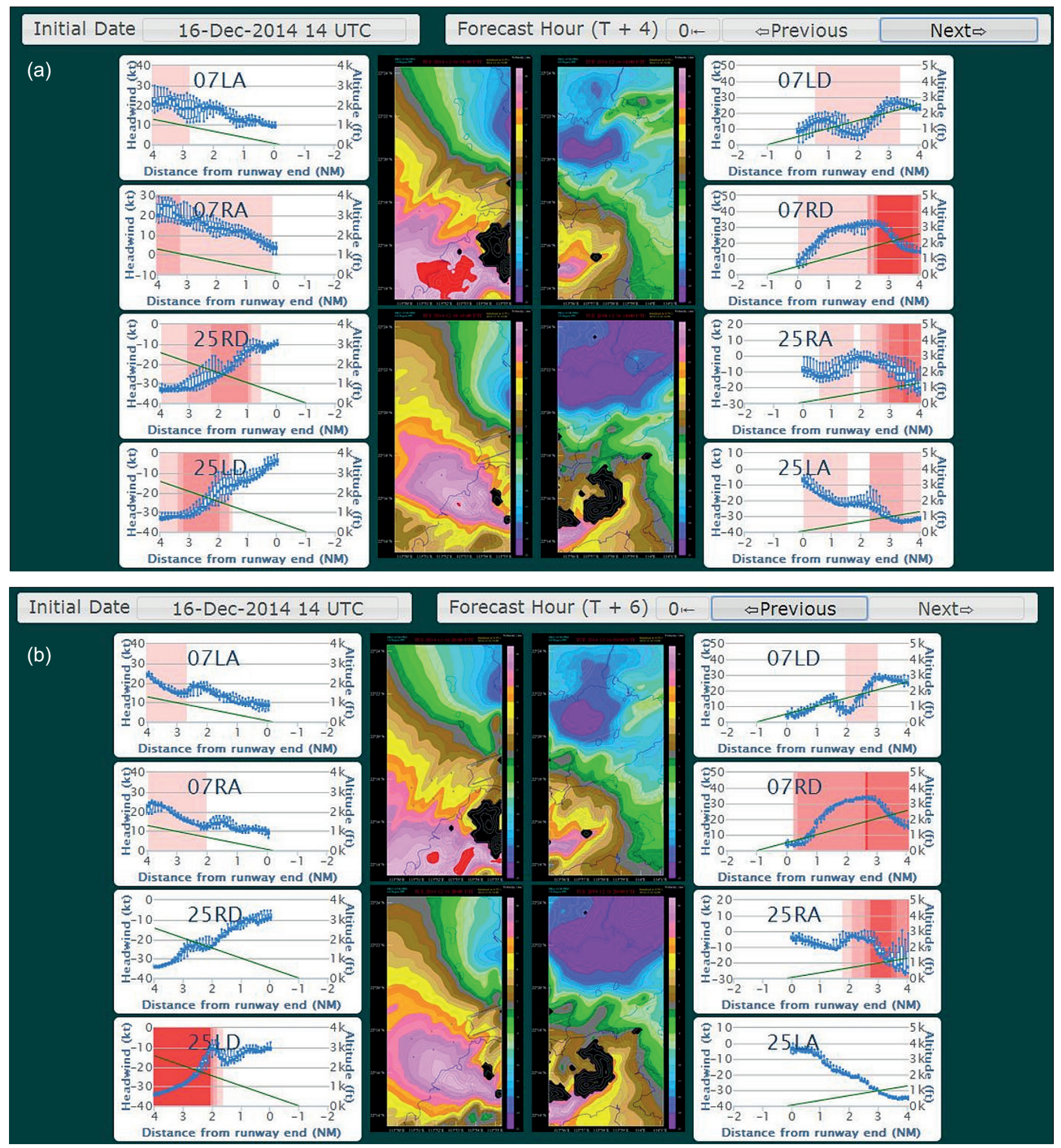

Fig. 12. Same as in Figure 6 but for the intense northeast monsoon case. (a) 4-h forecast, and (b) 6-h forecast, both initialized at 14:00 UTC, December 16, 2014. 


\section{Summary}

Windshear associated to low-level jets under the northeast monsoon regime in Hong Kong is studied in this paper, with two typical examples, namely, terrain disruption of easterly jet, and outbreak of northerly surge bringing intense northeasterly jet. As a result of the jet, headwind profiles along the flight path of landing and departing aircrafts affected by windshear show single peak or even double peak structures. In particular, the double peak feature in the headwind profiles is traceable to a meso- to micro-scale double-jet structure within the boundary layer which has not been reported in the literature before. This documentation is expected to serve as a useful reference for aviation weather forecasters in alerting low-level windshear associated with boundary layer jet streams. The capability of a high-resolution NWP model for predicting jet-related windshear under the northeast monsoon regime is also documented in this paper. In general, the NWP model performs well in capturing the corresponding windshear. The predicted wind field in the region of HKIA, in the form of simulated LIDAR planar scan return, is reasonable as compared to actual observations. The predicted headwind profile captures the main features of the windshear; however, further improvement is still required to predict and better understand the double jet structure, which is rather rare at HKIA. Future work in this regard will be reported in upcoming papers.

\section{References}

Chan PW, Chan ST. 2004. Performance of eddy dissipation rate estimates from wind profilers in turbulence detection, 11th Conference on Aviation, Range, and Aerospace Meteorology, American Meteorological Society, Hyannis, MA, USA, 4-8 October. Available at: https://www.hko.gov.hk/en/publica/reprint/files/ r553.pdf

Chan PW, Hon KK. 2016. Performance of super high resolution numerical weather prediction model in forecasting terrain-disrupted airflow at the Hong Kong International Airport: Case studies. Meteorological Aplications 23: 101-114. https://doi.org/10.1002/ met.1534

Chan PW, Hon KK, Li QS. 2019. A more comprehensive study of terrain-disrupted airflow at the 2 Hong Kong International Airport - Observations and numerical simulations. Weather (accepted). https://doi. org/10.1002/wea.3593

Chang KM. 1989. Prediction of the strength of overnight easterly winds in Hong Kong in winter. HKO Technical Note No. 79. Available at: https://www.hko.gov.hk/en/ publica/tn/files/tn079.pdf

Du Y, Chen G. 2018. Heavy rainfall associated with double low-level jets over southern China. Part I: Ensemble-based analysis. Monthly Weather Review 146: 3827-3844. https://doi.org/10.1175/ MWR-D-18-0101.1

Du Y, Chen G. 2019. Climatology of Low-level jets and their impact on rainfall over southern China during the early-summer rainy season. Journal of Climate 32: 8813-8833. https://doi.org/10.1175/JCLI-D-19-0306.1 HKO. 2013. Windshear and turbulence in Hong Kong Information for pilots. 3rd ed. Available at: https:// www.hko.gov.hk/en/aviat/articles/files/WS-turb-booklet-eng-3rd.pdf

Hon KK. 2018. Simulated satellite imagery at sub-kilometre resolution by the Hong Kong Observatory. Weather 73: 139-144. https://doi.org/10.1002/wea.3100

Hon KK. 2019. Predicting low-level windshear using 200-m resolution NWP at the Hong Kong International Airport, Journal of Applied Meteorology and Climatology (accepted). https://doi.org/10.1175/ JAMC-D-19-0186.1

Hon KK, Tse SM, Chan PW, Li QS. 2019. Observation and real-time simulation of a tornado event in Hong Kong on 29 August 2018. Advances in Meteorology 2019: 8571430. https://doi.org/10.1155/2019/8571430

Iacono MJ, Delamere JS, Mlawer EJ, Shephard MW, Clough SA, Collins WD. 2008. Radiative forcing by long-lived greenhouse gases: Calculations with the AER radiative transfer models. Journal of Geophysical Research-Atmospheres 113: D13103. https://doi. org/10.1029/2008JD009944

Lai ST. 1989. Short-range forecasting of northerly surges. HKO Technical Note No. 83. Available at: https://www. hko.gov.hk/en/publica/tn/files/tn083.pdf

Leung YT, Cheung HN, Zhou W. 2015. Energetics and dynamics associated with two typical mobile trough pathways over East Asia in boreal winter. Climate Dynamics 44: 1611-1626. https://doi.org/10.1007/ s00382-014-2355-6

Lim K-SS, Hong S-Y. 2010. Development of an effective double-moment cloud microphysics scheme with prognostic cloud condensation nuclei $(\mathrm{CCN})$ for weather 
and climate models. Monthly Weather Review 138: 1587-1612. https://doi.org/10.1175/2009MWR2968.1 Niu GY, Yang Z-L, Mitchell KE, Chen F, Ek MB, Barlage M, Kumar A, Manning K, Niyogi D, Rosero E, Tewari M, Xia Y. 2011. The community Noah land surface model with multiparameterization options (Noah-MP): 1. Model description and evaluation with local-scale measurements. Journal of Geophysical Research 116: D12109. https://doi.org/10.1029/ 2010JD015139

Shu ZR, Li QS, He YC, Chan PW. 2018. Investigation of low-level jet characteristics based on wind profiler observations. Journal of Wind Engineering and Industrial Aerodynamics 174: 369-381. https://doi. org/10.1016/j.jweia.2018.01.035

Shun CM, Chan PW. 2008. Applications of an infrared Doppler lidar in detection of wind shear. Journal of Atmospheric and Oceanic Technology 25: 637-655. https://doi.org/10.1175/2007JTECHA1057.1

Skamarock WC, Klemp JB. 2007. A time-split nonhydrostatic atmospheric model for weather research and forecasting applications. Journal of Computational Physics 227: 3465-3485. https://doi.org/10.1016/j. jcp.2007.01.037 